\title{
The effect of some physiological stimuli on fibrinolytic activity in man measured by the heparin fractionation method
}

\author{
W. B. THOMSON, J. GREEN, AND I. LYNN EVANS \\ From St. Mary's Hospital and Paddington General Hospital, London
}

The recently reported heparin fractionation method for measuring fibrinolytic activity in plasma (Green, 1959; Green and Thomson, 1962) has been used to re-examine the effect of certain physiological stimuli on fibrinolytic activity in man. In addition to providing further data on factors influencing natural fibrinolytic activity such a study afforded a means of assessing the value and sensitivity of the heparin fractionation method in the investigation of fibrinoylsis. For this reason dilute whole blood lysis times (Fearnley, Balmforth, and Fearnley, 1957) were measured on most samples to act as a reference for the heparin fraction lysis times.

The fibrinolytic activity of blood may be altered generally or the change may be confined to a localized part of the circulation. General and local changes in fibrinolytic activity will be considered separately below.

\section{GENERAL CHANGE IN FIBRINOLYTIC ACTIVITY}

METHOD In these experiments changes in fibrinolytic activity in venous blood were measured after exercise or after the administration of various naturally occurring substances by the intravenous, subcutaneous, or oral routes. The subjects were all normal young adults. They had fasted and abstained from smoking for at least four hours and had rested for at least half an hour. Blood was obtained from an antecubital vein with minimum stasis for estimation of visual lysis and in some cases proteolytic activity and esterolytic activity against lysine ethyl ester and tosyl arginine methyl ester. In most experiments $0.2 \mathrm{ml}$. of each blood sample was added to $1.8 \mathrm{ml}$. phosphate buffer for measurement of dilute whole blood lysis time. Two control samples were taken at intervals of five to 15 minutes and then the stimulus was applied. A third sample was obtained when the effects of the stimulus were probably maximal, as judged by other physiological observations such as pulse rate, blood pressure, skin colour, or the development of symptoms. While the effects of the stimulus were wearing off at least two further blood samples were taken to show a return of activity towards control values as confirmation that any change noted in the third sample was a true response to the stimulus applied.

RESULTS WITH COMMENTS The stimuli studied and the results obtained are summarized in Table $I$. The effects of emotion, food substances, alcohol, and steroid hormones were not studied.

Exercise Six subjects took a walk lasting 15 to 20 minutes which was sufficiently brisk to produce slight sweating or tachycardia. All subjects showed

TABLE I

\begin{tabular}{|c|c|c|c|c|c|}
\hline Stimulus & $\begin{array}{l}\text { No. of } \\
\text { Subjects }\end{array}$ & Dose & Route & Physiological Effects & Change in Fibrinolysis \\
\hline Exercise & 6 & $15-30 \mathrm{~min}$ & 一 & Mild sweating, tachycardia (6) & Increased activity all subjects \\
\hline Adrenaline & 6 & $0.25-0.5 \mathrm{mg}$ & Subcutaneous & $\begin{array}{l}\text { Pallor, tachycardia, } \\
\text { apprehension (6) }\end{array}$ & Increased activity all subjects \\
\hline Noradrenaline & 3 & $8-16 \mu \mathrm{g} . / \mathrm{min}$. & Intravenous & $\begin{array}{l}\text { Pallor (B.P. } 110 / 70 \text { to } \\
150 / 90 \mathrm{~mm} \text {. Hg), bradycardia (3) }\end{array}$ & None \\
\hline$\beta$-Methyl acetylcholine & 3 & $10-30 \mathrm{mg}$. & Subcutaneous & $\begin{array}{l}\text { Slight tachycardia (2) } \\
\text { Abdominal colic (1) }\end{array}$ & None \\
\hline Histamine & 4 & $\begin{array}{l}50 ; 80 \mu \mathrm{g} . / \mathrm{min} . \\
0.5 ; 0.9 \mathrm{mg} .\end{array}$ & $\begin{array}{l}\text { Intravenous } \\
\text { Subcutaneous }\end{array}$ & $\begin{array}{l}\text { Facial flushing (4) } \\
\text { Headache (3) }\end{array}$ & None \\
\hline 5-Hydroxytryptamine & 8 & $350-2,170 \mu \mathrm{g}$. & Intravenous & $\begin{array}{l}\text { Pain in arm injected (5) } \\
\text { Slight 'warmth' (3) }\end{array}$ & $\begin{array}{l}\text { Slight increase in two } \\
\text { (? apprehension) }\end{array}$ \\
\hline Nicotinic acid & 5 & $100-200 \mathrm{mg}$. & Oral & Facial flushing (2) & $\begin{array}{l}\text { Increased activity in two, who } \\
\text { showed flush }\end{array}$ \\
\hline Heparin & 1 & $1 \mathrm{mg}$. & Intravenous & None & None \\
\hline
\end{tabular}




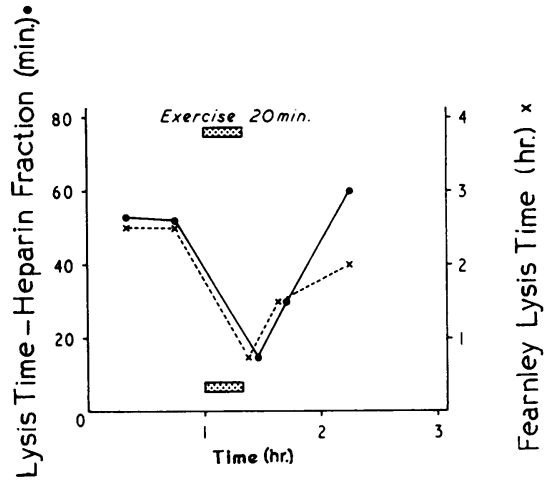

FIG. 1. Effect of exercise on fibrinolytic activity in one subject.

increased fibrinolytic activity in venous blood samples immediately after exercise but the activity had returned to control values within $\mathbf{3 0}$ minutes in five subjects and 60 minutes in one subject (Fig. 1).

Adrenaline In all six subjects tested $0 \cdot 2$ to $0.5 \mathrm{mg}$. adrenaline reduced lysis times to between $25 \%$ and $70 \%$ of control values. The effect was maximal 10 to 30 minutes after injection and values had returned to control levels in the final 60-minute sample in five subjects. The production of increased fibrinolysis by adrenaline was first reported by Biggs, McFarlane, and Pilling (1947) and has been confirmed many times since by a variety of methods.

Noradrenaline In three subjects noradrenaline infusions of 8,12 , and $16 \mu \mathrm{g}$./min. respectively produced pallor, increases in blood pressure of the order of $110 / 70$ to $150 / 90 \mathrm{~mm}$. $\mathrm{Hg}$, and a reflex bradycardia but no change in fibrinolytic activity. This contrasts with the finding of Genton, Kern, and von Kaulla (1961) of reduced euglobulin lysis times in all three subjects receiving noradrenaline infusions. Their subjects experienced fairly severe symptoms such as occipital headache, breathlessness, and low back pain, and had blood pressure rises to 200 to $220 \mathrm{~mm}$. Hg systolic so that the observed increase in activity might have been due to the use of larger amounts of noradrenaline or possibly to apprehension causing a release of endogenous adrenaline.

$\beta$-Methyl acetylcholine The $\beta$-methyl analogue was used because it is less rapidly destroyed than acetylcholine itself. No change in fibrinolytic activity was seen with doses of 10 to $30 \mathrm{mg}$. subcutaneously in three subjects. Soulier and Koupernik (1948) reported increased fibrinolytic activity with large doses of acetylcholine so perhaps the negative results obtained here are due to smaller doses or to the use of the $\beta$-methyl analogue.
Histamine Some facial flushing and headache $\stackrel{0}{F}$ was experienced by all four subjects but no change $\underline{\text { ㅇ }}$ in fibrinolytic activity was observed.

5-Hydroxytryptamine of eight subjects given $\stackrel{\overline{\bar{F}}}{+}$ intravenous injections of 5-hydroxytryptamine, two을 showed a slight increase in fibrinolytic activity. 음 Both subjects were apprehensive after painful $\frac{\infty}{\vec{\sigma}}$

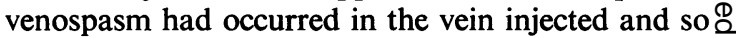
the increased activity might have been due to release $\$$ of endogenous adrenaline. Failure to observe $a \vec{a}$ consistent and significant change in fibrinolysis is ${ }^{\circ}$ surprising in view of the report of Kwaan, Lo, and $\vec{\omega}$ McFadzean (1957a) that 1 to $5 \mu \mathrm{g}$. serotonin $\cong$ intravenously produces increased activity in the blood of the vein used for injection.

\section{LOCAL CHANGES IN FIBRINOLYTIC ACTIVITY}

EFFECTS OF INTRA- AND PERIVENOUS ADRENALINE The 오 effects of intra- and perivenous adrenaline were $\overrightarrow{-}$ studied in three conscious normal young adult males and one young adult female undergoing a varicose vein stripping operation under a general $\vec{\emptyset}$ anaesthetic.

A cannula pointing towards the wrist was insertedo into an antecubital vein and blood samples taken before, during, and two and five minutes after the injection of 2 to $4 \mu \mathrm{g}$. adrenaline directly into (two subjects) or near (one subject) a direct venous $\mathbb{Q}$ tributary at the wrist.

Adrenaline, $2 \mu \mathrm{g}$., was injected into the saphenous vein at the ankle and blood sampled from the same vein at the groin after the femoral and saphenous vessels had been exposed surgically with the patient under a general anaesthetic.

No change in fibrinolytic activity was seen in any음 subject.

EFFECTS OF INTRA-ARTERIAL INJECTION OF PHYSIO-Э LOGICAL SUBSTANCES Fibrinolytic, proteolytic, and응 esterolytic activity against lysine ethyl ester and $>$ tosyl arginine methyl ester were measured in femoralo venous blood after the injection of various physio- $\bar{N}$ logical substances into the femoral artery of the same leg.

The observations were made on volunteer patients $\sigma$ undergoing varicose vein stripping operations under general anaesthetic. The anaesthetic varied slightly in different subjects but usually consisted of premedication with omnopon, induction with thiopentone and succinyl-:choline, and maintenance with nitrous oxide, oxygen, and $\frac{T}{T}$ occasionally halothane or pethidine. The observations $\overrightarrow{+}$ were made after the exposure of the femoral and $\stackrel{\Phi}{ }$ saphenous vessels in the groin and before the stripping procedure was began. Femoral vein samples were obtained $\sigma$ with a polyethylene catheter introduced via the saphenous 
TABLE II

LOCAL CHANGE IN FIBRINOLYSIS

\begin{tabular}{|c|c|c|c|c|}
\hline Substance & $\begin{array}{l}\text { No. of } \\
\text { Subjects }\end{array}$ & Dose & Physiological Effects & Change in Fibrinolysis \\
\hline Adrenaline & 7 & $\begin{array}{l}1.5 \mu \mathrm{\mu g} .(1) \\
3.0 \mu \mathrm{g} .(1) \\
9.0 \mu \mathrm{g} .(5)\end{array}$ & $\begin{array}{l}\text { None } \\
\text { None } \\
\text { Fall in blood pressure and } \\
\text { tachycardia in one }\end{array}$ & $\begin{array}{l}\text { None } \\
\text { None } \\
\text { Increased activity in four, } \\
\text { none in one }\end{array}$ \\
\hline $\begin{array}{l}\text { Noradrenaline } \\
\text { Iso-propyl-noradrenaline }\end{array}$ & $\begin{array}{l}3 \\
2\end{array}$ & $\begin{array}{l}9 \mu \mathrm{g} . \\
0.3 \mu \mathrm{g} . \\
0.6 \mu \mathrm{g} .\end{array}$ & $\begin{array}{l}\text { None } \\
\text { None }\end{array}$ & $\begin{array}{l}\text { None } \\
\text { None }\end{array}$ \\
\hline Acetylcholine & 2 & $\begin{array}{l}20 \mathrm{mg} . \\
50 \mathrm{mg}\end{array}$ & $\begin{array}{l}\text { Transient flush on leg } \\
\text { None }\end{array}$ & $\begin{array}{l}\text { Increased activity } \\
\text { Doubtful increase }\end{array}$ \\
\hline Histamine & 3 & $\begin{array}{r}10 \mu \mathrm{\mu g} .(2) \\
100 \mu \mathrm{g} .(1)\end{array}$ & $\begin{array}{l}\text { Transient flush in thigh in one } \\
\text { Generalized flush }\end{array}$ & $\begin{array}{l}\text { None } \\
\text { Increased activity both in } \\
\text { femoral vein and left hand blood }\end{array}$ \\
\hline $\begin{array}{l}\text { 5-Hydroxytryptamine } \\
\text { Heparin } \\
\text { Urokinase }\end{array}$ & $\begin{array}{l}1 \\
1 \\
2\end{array}$ & $\begin{array}{l}15 \mu \mathrm{g} \\
0 \cdot 25 \mathrm{mg} . \\
5,000 \text { units }\end{array}$ & $\begin{array}{l}\text { None } \\
\text { None } \\
\text { None }\end{array}$ & $\begin{array}{l}\text { None } \\
\text { None } \\
\text { Increased activity }\end{array}$ \\
\hline
\end{tabular}

vein and then treated as indicated previously. In addition, blood was taken by venepuncture from the patient's left hand at about the time maximal activity was expected in femoral vein blood to confirm that any change of activity was confined to the leg. The doses of the various substances used were those known from the medical literature to have a definite physiological effect under similar experimental conditions in conscious subjects.

The stimuli studied and the results obtained are summarized in Table II.

Adrenaline Doses of $1.5 \mu \mathrm{g}$. and $3 \mu \mathrm{g}$. showed no effect but giving $9 \mu \mathrm{g}$., which was shown by Ginsburg and Cobbold (1960) to alter blood flow in the limb when given intra-arterially, produced a definite increase in fibrinolytic, proteolytic, and esterolytic activity in four of five subjects (Fig. 2). In the subject who showed no change there was a pronounced fall in blood pressure and a tachycardia occurring immediately after the injection and lasting for five to 10 minutes.

Noradrenaline No effect was seen.

Isopropylnoradrenaline No effect was seen.

Acetylcholine In view of the apparent inactivity of $\beta$-methyl-acetylcholine when given systemically we were surprised to see increased fibrinolytic

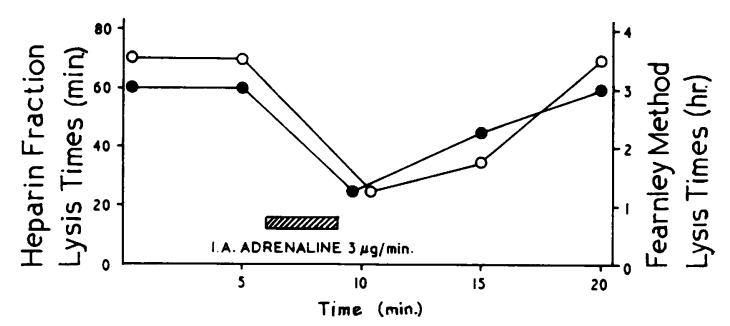

FIG. 2. Effect of intra-arterial adrenaline on fibrinolytic activity in one subject. activity after $20 \mathrm{mg}$. acetylcholine intra-arterially. In this subject a transient flush occurred on the thigh immediately after the injection, but in the other subject no flush and only a doubtful slight increase in activity was seen with $50 \mathrm{mg}$. acetylcholine.

Histamine Stead and Warren (1944) demonstrated increased capillary permeability in the forearm after 100 to $150 \mu \mathrm{g}$. histamine injected into the brachial artery. In our experimental conditions $100 \mu \mathrm{g}$. histamine intra-arterially produced a generalized flushing of the skin within half to one minute of injection and a generalized increase of fibrinolytic activity as indicated by a rise of activity in the left hand vein as well as in the femoral vein sample. This result is in contrast to the lack of effect of intravenous and subcutaneous histamine noted in Table I. A transient flushing of the leg was seen in one of the two subjects receiving $10 \mu \mathrm{g}$. but no change in fibrinolytic activity was observed in either patient.

5-Hydroxytryptamine In view of the powerful and prolonged vasoconstrictor effects of this substance it was given only to one subject who was about to undergo amputation of the leg for arteriosclerotic gangrene. No change in fibrinolytic activity was observed.

Heparin No effect was seen.

Urokinase Urokinase, 5,000 u. intra-arterially, produced a marked increased in fibrinolytic, proteolytic, and esterolytic activity in both patients. An example is given in Figure 3.

\section{CONCLUSIONS}

VALUE OF THE HEPARIN FRACTIONATION METHOD The close agreement between the heparin fractionation method and the dilute whole blood lysis method of Fearnley et al. (1957) confirms the usefulness of the former method in the study of fibrinolysis in man. 

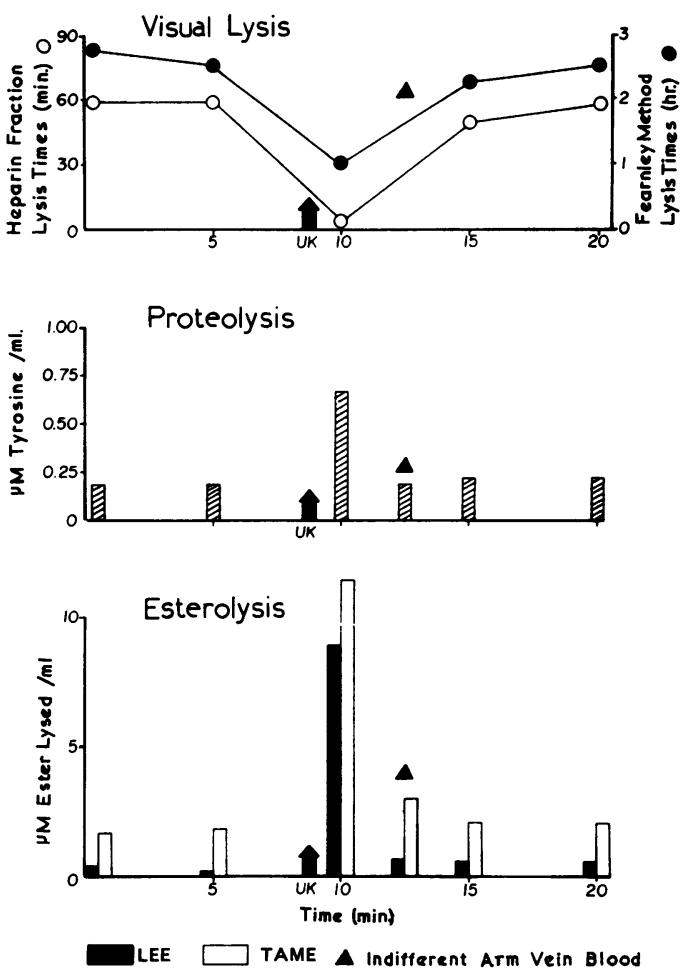

FIG. 3. Effects of intra-arterial urokinase on fibrinolytic, proteolytic, and esterolytic activity in one subject.

EXERCISE Our finding of increased fibrinolytic activity after exercise is in agreement with that of Biggs et al. (1947) and the majority of other reports since then. The mechanism of this effect of exercise remains unexplained.

ADRENALINE This is the first demonstration of increased fibrinolysis in peripheral venous blood following the intra-arterial injection of adrenaline. It confirms the suggestion by Kwaan, Lo, and McFadzean (1957b) that adrenaline can increase fibrinolysis by a peripheral action and does not necessarily produce its effects by an action on an organ such as the liver. In a small number of experiments we were unable to confirm the report by Kwaan et al. (1957b) that intra- or perivenous injections of adrenaline produce increased fibrinolysis in local venous blood. However, there is little doubt that in our experiments adrenaline was the $\overrightarrow{\overrightarrow{5}}$ only naturally occurring substance which consist ently produced an increase in fibrinolytic activityo whether given systemically or intra-arterially. Thise finding, which is shared by most other workers, $\bar{D}$ suggests that adrenaline might play an importanto role in physiological fibrinolysis, and further study ${ }^{\infty}$ of the mechanism of its effect might give vita $\vec{p}$ information on the control of natural fibrinolysis.

UROKINASE The increase in fibrinolytic activityo resulting from 5,000 units urokinase was approximately equivalent to that induced by $9 \mu \mathrm{g}$. adrenaline given under similar experimental conditions.

OTHER SUBSTANCES Acetylcholine appeared to stimulate fibrinolysis when given intra-arterially and this requires further study, but our experimentsoffer no support for an important role in physio logical fibrinolysis for histamine, heparin, or5-hydroxytryptamine. It is perhaps worth notingo that with some substances, e.g., histamine, acetyl ${ }^{+}$ choline, and nicotinic acid, an increase in fibrinolytic activity was seen only when a skin flush was induced?

\section{REFERENCES}

Biggs, R., MacFarlane, R. G., and Pilling, J. (1947). Lancet, 1, 402. $\overrightarrow{\bar{D}}$ Fearnley, G. R., Balmforth, G., and Fearnley, E. (1957). Clin. Sci.,

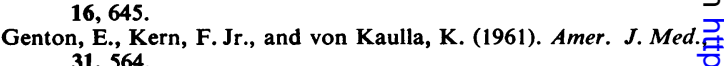
31, 564.

Ginsburg, J., and Cobbold, A. F. (1960). In Adrenergic Mechanisms edited by J. R. Vane, G. E. W. Wolstenholme, and M O'Connor, pp. 173-189. Churchill, London.

Green, J. (1959). Biochem. J., 71, 23P.

- and Thomson, W. B. (1962). Ibid., 84, 74P.

Kwaan, H. C., Lo, R., and McFadzean, A. J. S. (1957a). Clin. Sci. $16,255$.

(1957b). Ibid., 16, 241.

Soulier, J. P., and Koupernik, C. (1948). Sang, 19, 362.

Stead, E. A. Jr., and Warren, J. V. (1944). J. clin. Invest., 23, 279.

DR. STERN mentioned that when electro-shock was given to psychiatric patients there was a large increase in the blood level of adrenaline and noradrenaline. When sos called modified shock was given only the level of nor $N$ adrenaline rises. He had found that un-modified shock resulted in a pronounced increase of blood fibrinolytic ${ }^{\omega}$ activity whereas this effect was absent with modified electro-shock. 